$\begin{array}{cc}\text { ACADEMIA ROMÂNĂ } & \text { Rev. Roum. Chim., } \\ \mathbf{2 0 2 1}, \text { 66(3), 273-280 }\end{array}$

\title{
PHYSICO-CHEMICAL CHARACTERIZATION OF SOLID STATE REACTION BETWEEN TEREPHTALALDEHYDE AND p-AMINOPHENOL
}

\author{
Viorica MELTZER, Petruța OANCEA, Ioana STĂNCULESCU and Elena PINCU* \\ University of Bucharest, Department of Physical Chemistry, 030018 Bd. Regina Elisabeta 4-12, Bucharest, Roumania
}

Received September 30, 2020

The aim of this work was to investigate the possibilities of the solvent free synthesis of Schiff base (azomethyne) from terephthalaldehyde and p-aminophenol. The pure compounds and the reaction product were studied by differential scanning calorimetry (DSC), FTIR spectroscopy, UV-Vis spectroscopy and adiabatic combustion calorimetry. The structure of the reaction product was determined by FTIR spectroscopy. Spectral studies have shown that the reaction product is formed in a single stage. The standard enthalpy of reaction was obtained from heat of combustion of reactants and products and their value shows that the reaction is exothermic.

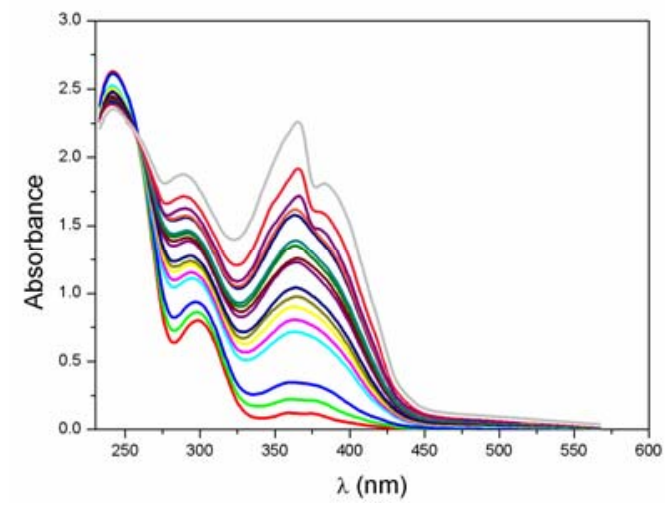

\section{INTRODUCTION}

Schiff bases or azomethines obtained from aromatic amines and aromatic aldehydes/ketones have a wide variety of practical applications in fields of interest such as biology and medicine. ${ }^{1}$ However, Schiff bases are chemically unstable and participate in a number of processes such as tautomeric interconversion. ${ }^{1-3}$ To eliminate these drawbacks, it is advantageous to synthesize them by a solvent-free (solid phase) reaction. ${ }^{4-7}$

These solid phase syntheses are part of the socalled "green chemistry", also known as "sustainable chemistry", that is the design and development of chemicals and processes that reduce or completely eliminate the use and generation of substances dangerous to humans and nature. ${ }^{8,9}$

Azomethines synthesis is very important because these products are widely used for obtaining thermosetting resins and liquid crystalline polymers. The $\mathrm{n}, \mathrm{n}^{\prime}$-terephthalylidene-bis-(4-aminophenol) is a rare chemical which is not very well characterized and many researchers synthesized it from terephthalaldehyde and $\mathrm{p}$-aminophenol in molar ratio $1: 2$ in different solvent media. ${ }^{10,11}$

In this work, the synthesis of n,n'terephthalylidene-bis-(4-aminophenol) from $\mathrm{p}$ aminophenol and terephthalaldehyde in solid phase and using solvent was investigated from physicochemical point of view. The n,n'-terephthalylidenebis-(4-aminophenol) obtained by grinding and

* Corresponding author: elena.pincu@chimie.unibuc.ro 
recrystallization from solvent in 1: 2 molar ratio was studied by FTIR spectroscopy, differential scanning calorimetry (DSC) and UV-Vis spectroscopy. The thermal effect of the reaction was determined from the heat of combustion obtained by adiabatic combustion calorimetry.

\section{RESULTS AND DISCUSSION}

The reaction between terephthalaldehyde and paminophenol takes place in 1:2 molar ratio ${ }^{10,11}$ and $\mathrm{n}, \mathrm{n}$-terephthalylidene-bis-(4-aminophenol) is obtained.<smiles>Cc1cc(N)ccc1O</smiles>

The synthesis of n,n'-terephthalylidene-bis-(4aminophenol) was made by two methods: solid phase reaction, in physical mixture, and solvent reaction, with ethanol.

In the first step, a homogeneous physical mixture (PM) of terephthalaldehyde and paminophenol in solid state with the molar ratio of 1:2 was obtained by weighing, mixing and grinding them for $15 \mathrm{~min}$. After grinding, a yellow product was obtained. The water produced in the reaction is fully absorbed by the reaction product.

Homogeneous solid mixtures of the same molar ratios were also made by dissolving the components in absolute ethanol and stirring continuously at room temperature until solvent evaporation (SE). After stirring, the solution color changed to yellow-green and a yellow solid was obtained after evaporation which means that the reaction between the components took place.

In order to determine the structure of the solid products obtained, the FTIR spectra were recorded for 1:2 molar ratio mixture obtained from the solvent evaporation (SE) and from the homogeneous physical mixture (PM) and are shown in the Figure 1.

The FTIR spectrum of the product obtained from the ethanol solution (Fig. 1) shows the following peaks: a wide peak at $3426.33 \mathrm{~cm}^{-1}$ characteristic of free $\mathrm{OH}$ bonds; at $3027.14 \mathrm{~cm}^{-1}$ and at $2873.53 \mathrm{~cm}^{-1}$ characteristic of the vibration of the $\mathrm{CH}$ bond in the aromatic nuclei and in the aliphatic chains respectively and at $1619.21 \mathrm{~cm}^{-1}$ characteristic of the vibration of the $\mathrm{C}=\mathrm{N}$ connection. The FTIR spectrum of the product shown that a n,n'-terephthalylidene-bis-(4aminophenol) is obtained from the condensation reaction. The disappearance of the peak at 1694 $\mathrm{cm}^{-1}$ characteristic of the $\mathrm{C}=\mathrm{O}$ bond present in the terephthalaldehyde and of the peaks from 3341.56 $\mathrm{cm}^{-1}$ and $3281.45 \mathrm{~cm}^{-1}$ characteristic of the $-\mathrm{NH}_{2}$ bond in p-aminophenol (Fig. 2) confirms that the reaction took place with total consumption of reactants.

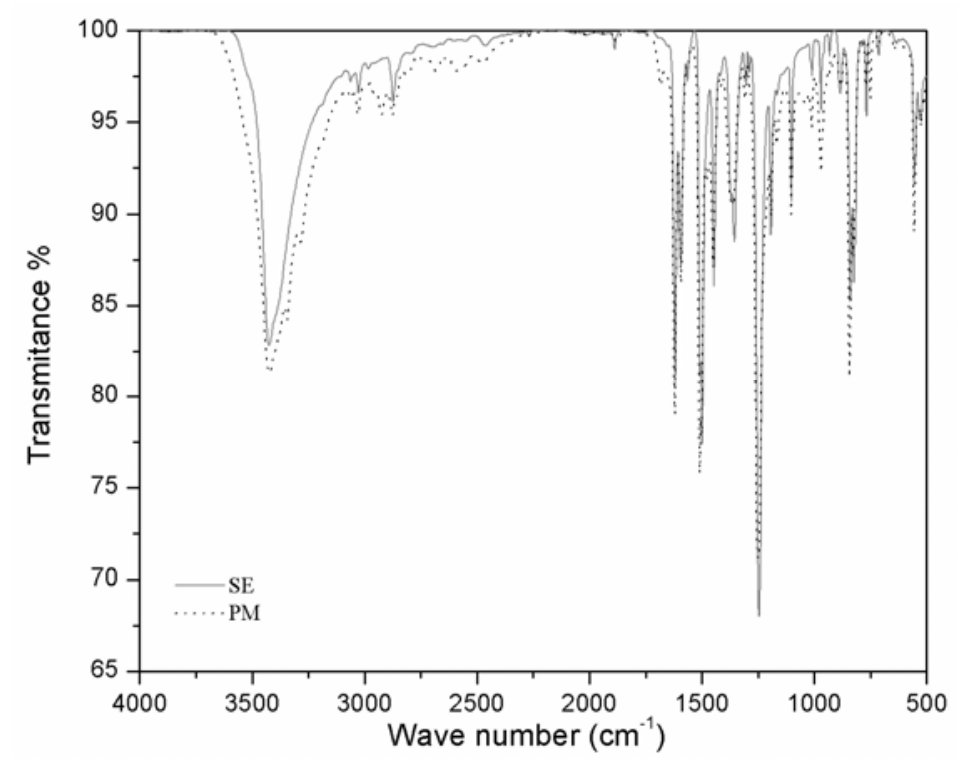

Fig. 1 - The FT-IR spectra for physical mixture (PM) and solvent evaporation (SE) in molar ratio 1:2 products. 


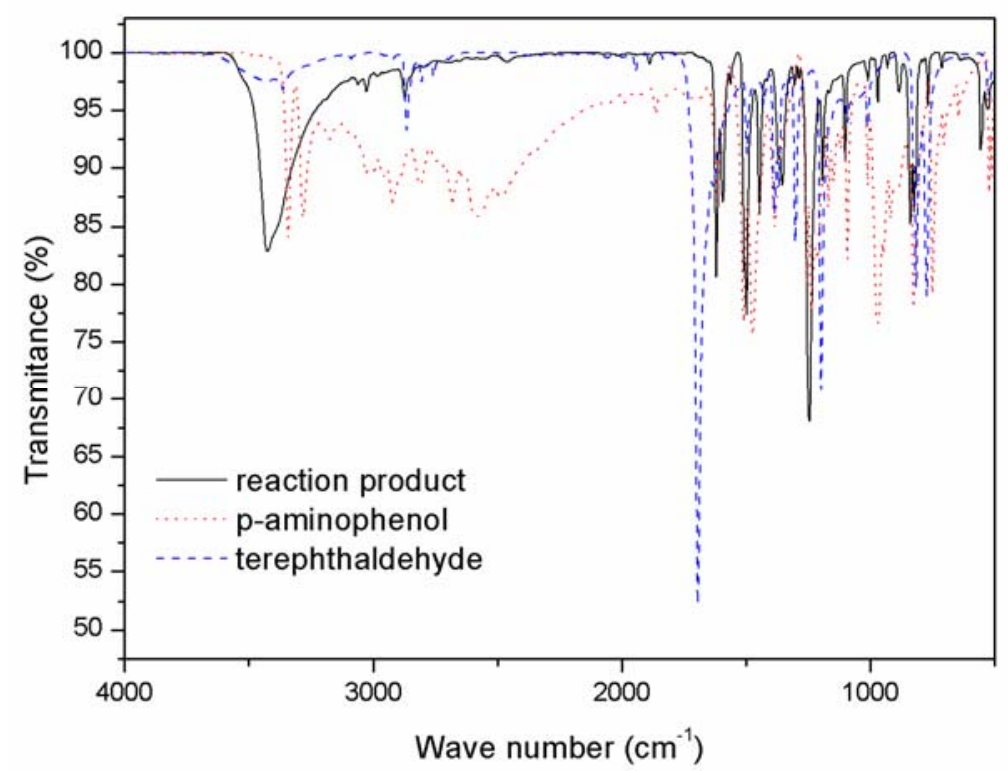

Fig. 2 - The FT-IR spectra for reaction product from ethanol, p-aminophenol and terephthalaldehyde.

The FTIR spectrum of the product obtained from the ground physical mixture shows the following peaks: at $3422.33 \mathrm{~cm}^{-1}$ characteristic of free $\mathrm{OH}$ bonds, a very small peak at $3342.92 \mathrm{~cm}^{-1}$ and at $3285.09 \mathrm{~cm}^{-1}$ characteristic of the $-\mathrm{NH}_{2}$ bond of 4-aminophenol, at $3028.57 \mathrm{~cm}^{-1}$ and at $2923.02 \mathrm{~cm}^{-1}$ characteristic of the vibration of the $\mathrm{CH}$ bond in the aromatic nuclei and in the aliphatic chains respectively, a very small peak at 1682.29 $\mathrm{cm}^{-1}$ characteristic of the $\mathrm{C}=\mathrm{O}$ bond of terephthalaldehyde, a large peak at $1620.31 \mathrm{~cm}^{-1}$ characteristic of the $\mathrm{C}=\mathrm{N}$ bond of azomethines. The appearance of small peaks characteristic of terephthalaldehyde and 4-aminophenol confirms that the solid phase reaction is not total. On the other hand, the appearance of the peaks at $3422.33 \mathrm{~cm}^{-1}$ as well as the one at $1620.31 \mathrm{~cm}^{-1}$ show that the product formed is identical to that obtained from ethanol, namely n,n'terephthalylidene-bis-(4-aminophenol).

The absorption spectra were recorded for terephthalaldehyde, p-aminophenol and for reaction product obtained from the solvent evaporation (SE) and from the homogeneous physical mixture (PM) and are shown in Fig 3. The product formed in the reaction presented a maximum absorption at $365 \mathrm{~nm}$.

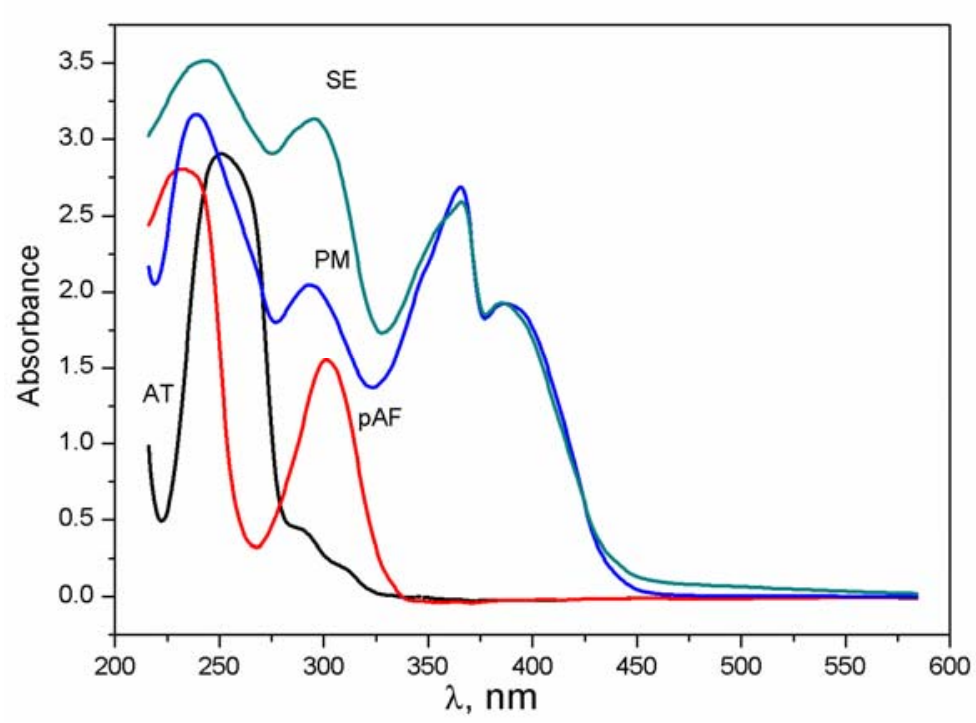

Fig. 3 - UV-Vis absorption spectra for physical mixture (PM) and solvent evaporation (SE) in molar ratio 1:2 and pure compounds (AT and pAF). 


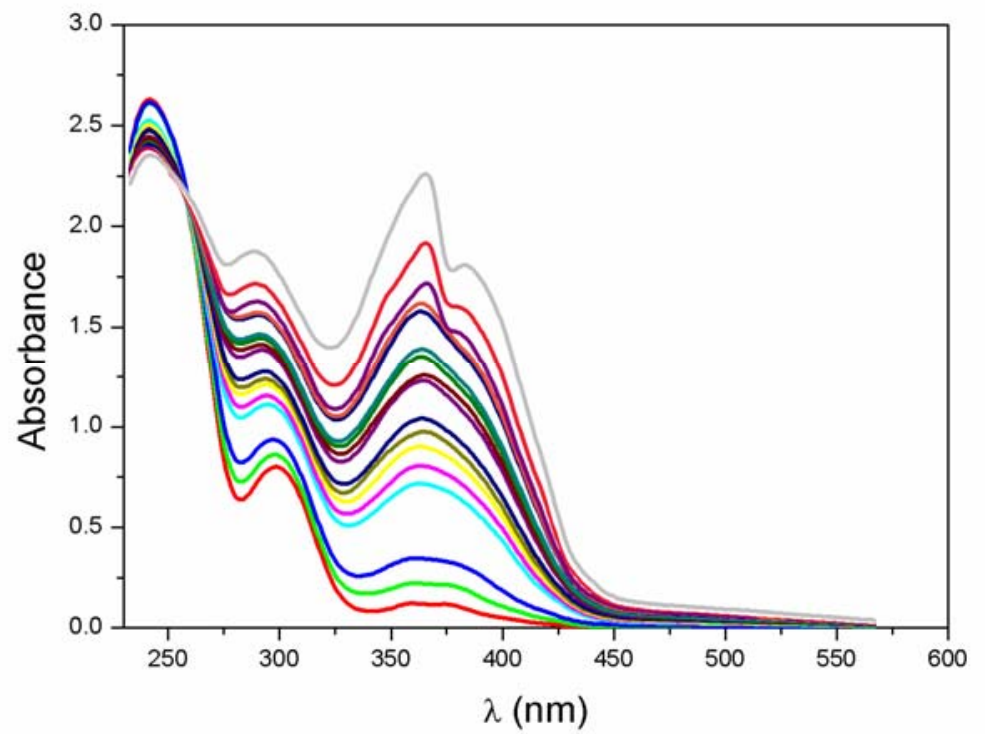

Fig. 4 - UV-Vis absorption spectra for reaction in ethanol in molar ratio AT:pAF = 1:2 .

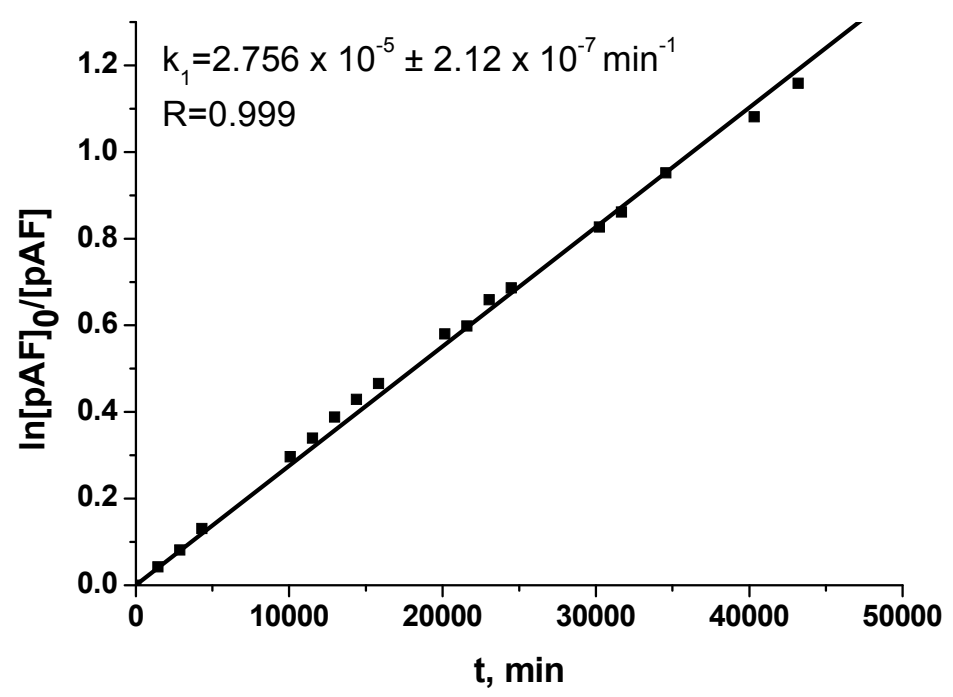

Fig. 5 - Pseudo-first-order reaction kinetics for pAF transformation.

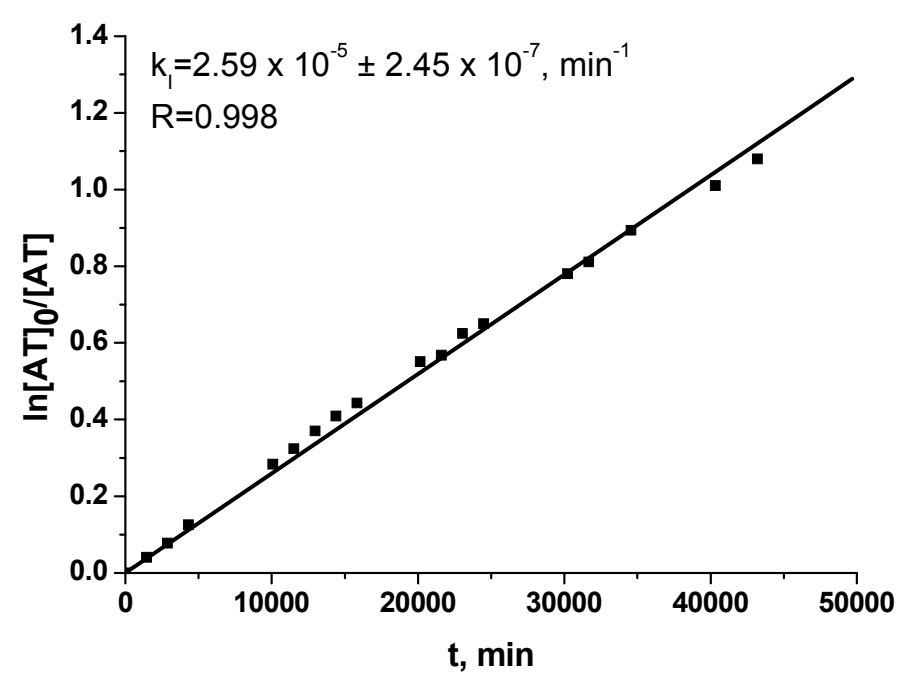

Fig. 6 - Pseudo-first-order reaction kinetics for AT transformation. 
The reaction in ethanol was studied in time for a 1:2 molar ratio and absorption spectra are presented in the Fig. 4.

The absorption spectrum shows the appearance of a new band in the range (335-430) $\mathrm{nm}$ corresponding to the formation of n,n'terephthalylidene-bis-(4-aminophenol). The band can be assigned to the $n-\pi^{*}$ transition of the $C=N$ conjugation. $^{12,13}$ It is observed that, the increase of the reaction time leads to the increase of the absorbance in the field in which the reactants do not absorb. At the same time, an isosbestic point appears at $260 \mathrm{~nm}$, which suggests the transformation of the reactants into the reaction product.

A plot of $\ln \left(\mathrm{A}_{0} / \mathrm{A}\right)$ vs. reaction time leaded to a linear dependence, characteristic to a pseudo-first order kinetics. Here $A_{0}$ is the absorbance at the beginning of the experiment and $\mathrm{A}$ is the instantaneous absorbance (at a certain time value).
The slopes represent the transformation kinetic constants: $\mathrm{k}=2.75 \times 10^{-5} \mathrm{~min}^{-1}$ (Fig. 5) and $2.59 \times$ $10^{-5} \mathrm{~min}^{-1}$ (Fig. 6) for $\mathrm{pAF}$ and AT, respectively. The estimated pseudo-first-rate constants for product formation $\mathrm{k}=4.0 \times 10^{-5} \mathrm{~min}^{-1}$ (Fig. 7) shows that the product is formed in a single stage. Terephthalaldehyde, 4-aminophenol and n,n'terephthalylidene-bis-(4-aminophenol) were thermally characterized by recording DSC curves. Thermodynamic parameters of the compounds are presented in Table 1 and represent average values for at least three experimental determinations.

The values of the melting temperatures and the melting enthalpies of compounds determined from the DSC curves are in accordance with the literature data.

The DSC curves obtained for terephthalaldehyde, 4-aminophenol and the two mixtures: physical mixture (PM) and solvent evaporation (SE) are shown in the Figure 8.

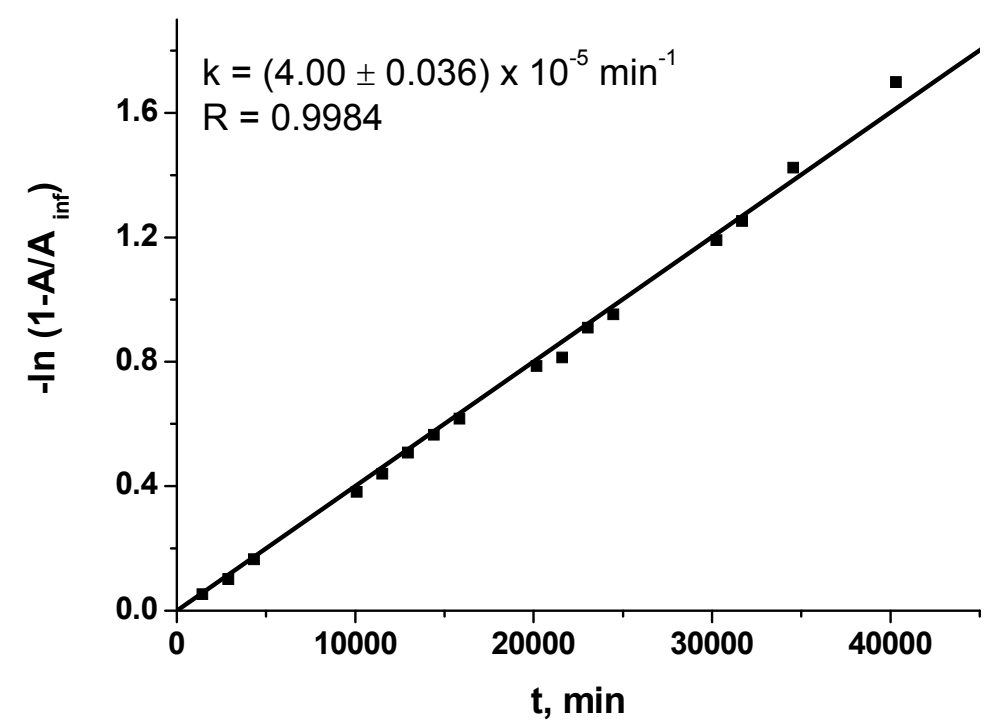

Fig. 7 - Pseudo-first-order reaction kinetics for product formation.

Table 1

Melting points, enthalpy of fusion and entropy of fusion of pure compounds

\begin{tabular}{c|c|c|c|c|c|c}
\hline \multirow{2}{*}{ Compound } & \multicolumn{2}{|c|}{$\mathbf{T}_{\mathbf{t}}(\mathbf{K})$} & \multicolumn{2}{c|}{$\Delta^{\mathbf{t}} \mathbf{H}\left(\mathbf{k J} \mathbf{~ m o l}^{-1}\right)$} & \multicolumn{2}{c}{$\Delta^{\mathbf{t} S}\left(J^{\mathbf{m o l}}{ }^{-1} \mathbf{K}^{-1}\right)$} \\
\cline { 2 - 7 } & Experimental & Literature & Experimental & Literature & Experimental & Literature \\
\hline Terephthalaldehyde (AT) & $386.39 \pm 0.19$ & $389^{14}$ & $23.26 \pm 0.21$ & - & $60.20 \pm 0.51$ & - \\
\hline 4-aminophenol (pAF) & $463.65 \pm 0.31$ & $462.5^{15} 459.5^{16}$ & $24.95 \pm 0.22$ & $26.00^{17}$ & $53.81 \pm 0.51$ & - \\
\hline $\begin{array}{c}\text { n,n'-terephthalylidene-bis-(4- } \\
\text { aminophenol) }\end{array}$ & $276.33 \pm 0.28$ & $274^{10}$ & $35.80 \pm 0.14$ & - & $129.54 \pm 0.51$ & - \\
\hline
\end{tabular}




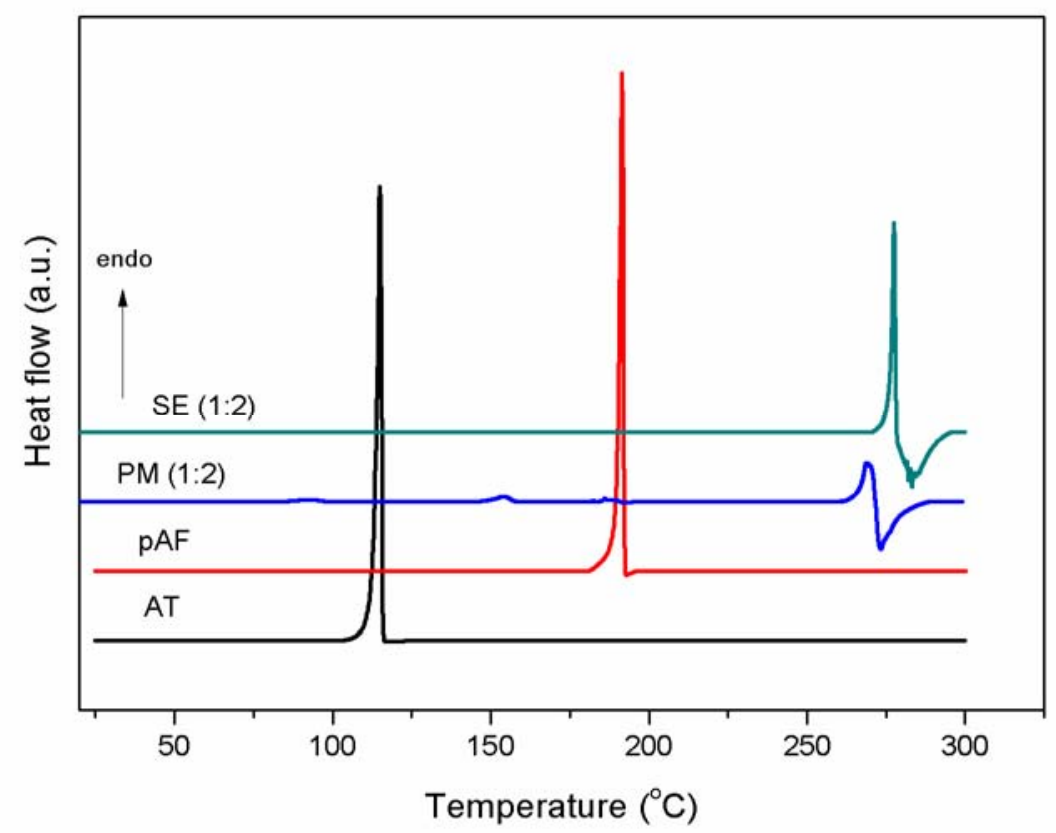

Fig. 8 - The DSC curves for terephthalaldehyde, 4-aminophenol and products, physical mixture (PM) respectively solvent evaporation (SE) in molar ratio 1:2.

The DSC curve obtained for the 1:2 molar ratio mixtures resulted from SE method showed an endothermic process at $276.33 \pm 0.28{ }^{\circ} \mathrm{C}$ with a melting enthalpy of $113.13 \pm 0.45 \mathrm{~J} / \mathrm{g}$ followed by an exothermic process which is attributed to the decomposition. In literature data the melting temperature of n,n'-terephthalylidene-bis-(4aminophenol) is reported ${ }^{10,18}$ at $274{ }^{\circ} \mathrm{C}$ and (256-262) ${ }^{\circ} \mathrm{C}$ respectively. The product obtained in this study was not recrystallized and has a higher melting temperature (decomposition), namely $276.33{ }^{\circ} \mathrm{C}$.

The missing of the endothermic processes characteristic to the terephthalaldehyde and 4-aminophenol suggested that reaction took place in solution and the water produces in the reaction was eliminated during the evaporation of ethanol.

On the other hand, the reaction in solid phase is not complete so that several processes are present in the DSC curve of the grinded physical mixture (PM) at $87{ }^{\circ} \mathrm{C}, 150^{\circ} \mathrm{C}$ and $184^{\circ} \mathrm{C}$ due to the water evaporation and unreacted terephthalaldehyde and 4-aminophenol. The melting and decomposition process attributed to the product is shifted to a lower temperature of $266^{\circ} \mathrm{C}$ than in the case of the product obtained from the solution $276.33{ }^{\circ} \mathrm{C}$ due to the presence in the system of the unreacted terephthalaldehyde and 4-aminophenol.

From the melting enthalpy of n,n'terephthalylidene-bis-(4-aminophenol) we calculated the reaction yield in solid phase and we obtained a value of $51.43 \pm 0.82 \%$.
These observations show that the reaction between terephthalaldehyde and 4-aminophenol took place with a $100 \%$ yield in solution and about $50 \%$ yield in solid phase. This is explained by the fact that in the solution the mobility and diffusion of molecules is very high while in solid phase the collision of molecules is not as efficient due to their low mobility.

The reaction between terephthalaldehyde and 4aminophenol in the solid phase can be thermodynamically characterized by determining its thermal effect at room temperature. The calculation of the heat of reaction was done using the heat of combustion of the reactants and reaction products.

The heats of combustion were theoretically calculated using the Handrick method which takes into account all the interactions present between the molecules. ${ }^{19]}$

The Handrick method is based on the following linear function:

$$
-\Delta^{c} H_{298}^{0}=\sum a^{\prime}+x \sum b^{\prime}\left(\mathrm{kJ} \cdot \mathrm{mol}^{-1}\right)
$$

where: a' and b' are constants and are tabulated for a large number of structural groups;

$\mathrm{x}$ is called the molar oxygen balance and represent the number of oxygen atoms required for combustion.

The experimental data compared with those calculated from group contributions method $^{20}$, which does not take into account the isomerism of the compounds, are presented in Table 2. 
Table 2

Heats of combustion for terephthalaldehyde, 4-aminophenol and n,n'-terephthalylidenebis(4-aminophenol)

\begin{tabular}{c|c|c|c}
\hline Compound & \multicolumn{3}{|c}{$-\Delta^{\mathbf{c}} \mathbf{H} \mathbf{~ ( k J ~ m o l ~}^{-1}$ ) } \\
\cline { 2 - 4 } & Experimental & Calculated & Literature \\
\hline Terephthalaldehyde (AT) & $3755.2 \pm 4.3$ & 3771.7 & - \\
4-aminophenol (pAF) & $3168.8 \pm 6.7$ & 3165.3 & $3167.4^{21}$ \\
n,n'-terephthalylidene-bis-(4-aminophenol) & $10008.8 \pm 3.9$ & 10014.6 & - \\
\hline
\end{tabular}

The combustion heats obtained experimentally for $p$-aminophenol are similar to those in the literature. No data were found for the terephthalaldehyde in the literature so that the experimentally determined value was compared with that calculated by the group contributions method. The same situation is found in the case of the reaction product.

The standard heat of reaction was calculated from the heats of combustion, and the value obtained was: $\Delta^{\mathrm{r}} \mathrm{H}_{298}^{0}=-84.0 \mathrm{~kJ} \cdot \mathrm{mol}^{-1}$.

The negative value of the standard enthalpy of reaction shows that the reaction is exothermic and may take place in the solid phase at room temperature.

\section{EXPERIMENTAL}

\section{Materials}

Terephthalaldehyde (Merck, $99 \mathrm{wt} \%$ ), 4-Aminophenol (Merck, 99.5 wt\%.) and ethanol (Fisher Chemicals, 99.99\%) were used without further purification.

The 1:2 (AT:pAF) molar ratio physical mixtures (PM) were prepared by weighing and grinding together at room temperature.

The solvent evaporation (SE) mixture of 1:2 molar ratio, was obtained by dissolving the reactants in ethanol and stirring the mixture continuously at room temperature until the evaporation of the solvent.

All masses were weighed with the Partner XA balance with a precision of $10 \mu \mathrm{g}$.

\section{Method and equipment}

Melting temperatures and melting enthalpies of pure components and mixtures of different compositions were determined with a differential scanning calorimeter (Perkin Elmer Diamond DSC) with heating rates of 10 degrees / minute in an inert argon atmosphere over the $(20-300){ }^{\circ} \mathrm{C}$ temperature range. The apparatus was calibrated for temperature and enthalpy by melting high purity indium. The samples were encapsulated in aluminum crucibles and the mass of the samples was about $4 \mathrm{mg}$.

FTIR spectra were obtained with a Bruker Vertex 70 spectrometer with the following parameters: resolution: $4 \mathrm{~cm}^{-1}$; wavenumber accuracy: $0.1 \mathrm{~cm}^{-1}$; photometric accuracy: $0.1 \% \mathrm{~T}$; spectral range: $(4000-400) \mathrm{cm}^{-1}$; beam splitter: $\mathrm{KBr}$; detector: RTDLaTGS. The measurements were performed by the technique of pastillation in $\mathrm{KBr}$ of spectroscopic purity (Merck reagent) at a mass ratio of $\mathrm{KBr}$ : Sample $=300$ : 1 .

The UV-vis spectra were recorded from $200 \mathrm{~nm}$ to $600 \mathrm{~nm}$ at room temperature $\left(\sim 25^{\circ} \mathrm{C}\right)$ using a UV-Vis spectrophotometer (Pye Unicam $\alpha$ Helios) with a spectrometric quartz cell $(1 \mathrm{~cm}$ path length) with a stopper to prevent evaporation of the solvent.

The heat of combustion was measured in an oxygen bomb combustion calorimeter model Parr equipped with a digital thermometer model 6775 , an oxygen bomb with an inner volume of $300 \mathrm{~mL}$ and a stirrer. The oxygen pressure during the experiment was (25-30) atm. The calibration of the calorimeter was done with a benzoic acid pill for which the calorific value is known $(\mathrm{q}=6318 \mathrm{cal} / \mathrm{g})$.

\section{CONCLUSIONS}

Experimental data have shown that the reaction between p-aminophenol and terephthalaldehyde takes place in solvent and in solid phase in homogeneous physical mixtures.

Spectral studies have shown that the reaction product is formed in a single stage in both variants and it is a dihydroxyazomethine, namely n,n'terephthalylidene-bis-(4-aminophenol).

The thermodynamic characterization of the n, n'terephthalylidene-bis-(4-aminophenol) formation reaction confirmed the possibility of a solid phase reaction with the formation of a stable product.

The importance of this study is the highlight of a reaction from the "green chemistry" class, a concept developed substantially in the last decade, promoting that side of chemistry that supports and respects nature, a chemistry friendly to humankind.

\section{REFERENCES}

1. M. N. Ibrahim and S. E. A. Sharif, E-J. of Chem., 2007, 4, 531-535.

2. Z. Cimerman and Z. Stefanac, Polyhedron, 1985, 4, 1755-1760.

3. N. Galic, Z. Cimerman and V. Tomisic, Anal. Chim. Acta, 1997, 343, 135-143. 
4. N. S. Khrushcheva, N. M. Loim and V. I. Sokolov, Russian Chem. Bull., 1997, 46, 1952-1955.

5. J. Schmeyers, F. Toda, J. Boy and G. Kaupp, J. Chem. Soc., Perkin Trans., 1998, 2, 989-993.

6. G. W. V. Cave, C. L. Raston and J. L. Scott, Chem. Commun., 2001, 21, 2159-2169.

7. V. Meltzer and E. Pincu, J. Chem. Thermod., 2011, 43, 1011-1016.

8. R. Hiraoka, H. Watanabe and M. Senna, Tetrahedron Letters, 2006, 47, 3111-3114.

9. P. T. Anastas, J. C. Warner, "Green Chemistry: Theory and Practice" Oxford University Press, 1998, p.30.

10. T. Giang and J. Kim, J. Ind. Eng. Chem., 2015, 30, 77-84.

11. M. Ochi and H. Takashima, Polymer, 2001, 42, 2379-2385.

12. R. C. Felicio, E. T. G. Cavalheiro and E. R. Dockal, Polyhedron, 2001, 20, 261-268.
13. D. N. Kumar and B. S. Garg, J. Therm. Anal. And Calorim., 2002, 69, 607-616.

14. J. Buckingham and S. M. Donaghy, "Dictionary of Organic Compounds:,Fifth Edition, Chapman and Hall, New York, 1982.

15. R. Sabbah and M. Gouali, Calorimetrie et Analyse Thermique, 1995, 26, $334-339$.

16. P. Bret-Dibat and A. Lichanot, Thermochim. Acta, 1989, 147, 261-271.

17. F. Nordström and A. Rasmuson, Eur. J. of Pharm. Sci., 2009, 36, 330-334.

18. M. S. Chattha (Ford Motor Company), US Pat. 4611046, sept. 9, 1986.

19. R. G. Handrick, Ind. \& Eng. Chem., 1956, 48, 1366-1374.

20. V. Meltzer, E. Pincu and G. Cristescu, "Energetică chimică", Editura Universitătii din București, 2010, p. 77-84.

21. R. Sabbah and M. Gouali, Can. J. Chem., 1996, 74, 500-507. 